\title{
Characteristics of Top Tier Finance Journal Publications
}

\author{
Ebenezer Asem ${ }^{1} \&$ Vishaal Baulkaran ${ }^{1}$ \\ ${ }^{1}$ Faculty of Management, University of Lethbridge, Lethbridge, Alberta, Canada \\ Correspondence: Vishaal Baulkaran, Faculty of Management, University of Lethbridge, Lethbridge, AB, T1K \\ 3M4, Canada. Tel: 1-403-329-2074. E-mail: vishaal.baulkaran@uleth.ca
}

Received: October 4, 2016

Accepted: November 3, $2016 \quad$ Online Published: November 20, 2016

doi:10.5539/ijef.v8n12p50

URL: http://dx.doi.org/10.5539/ijef.v8n12p50

\begin{abstract}
This paper examines the characteristics of "top tier" finance journal publications relative to "second tier" finance publications. We study ten leading finance journals and classify the top four journals as "top tier" and the remaining six as "second tier" journals. Using a sample of 3,156 different articles with 7,103 different authors and a Logit model, the results highlight the following characteristics: papers presented at WFA, AFA, and seminars, and have multiple colleague comments tend to be published in the top tier journals. Also, authors who graduated from or are affiliated with the top business schools tend to publish in the top tier journals.
\end{abstract}

Keywords: publishing, co-authorship, conferences, seminars

\section{Introduction}

Publication in top finance journals sets the path for a very successful academic career and most finance academics, and even practitioners strive to publish in these journals. Yet, there is no comprehensive study of the factors that contribute to publishing in these top tier journals. We address this important issue by studying the characteristics of articles published in the top four finance journals ("top tier" journals) and those of articles published in the next six journals ("second tier" finance journals) to ascertain the features that are influential in publishing in the top tier journals versus the second tier journals (Note 1).

The characteristics we study include: (i) the number of conferences that the article was presented at, (ii) whether the article was presented at the American Finance Association (AFA), the Western Finance Association (WFA) or the Financial Management Association (FMA) conference, (iii) the number of seminars that the article was presented at, (iv) whether the research was funded, (v) the number of referees, (vi) the number of colleague that commented on the article, (vii) the number of authors, (viii) the author's affiliation, and (ix) the author's PhD granting institution.

We document several differences in the characteristics of the papers published in the top tier journals and those published in the second tier journals. First, our results show that papers published in the top tier journals tend to be presented at the AFA and the WFA more than papers published in the second tier journals. In contrast, papers published in the second tier journals tend to be presented at the FMA more than papers published in the top tier journals. This is likely because the WFA and the AFA are more selective conferences, making our results consistent with Johnson, Kalay and Schallheim (2002) finding that presenting a paper at a selective conference increases the probability of publishing it in a top tier journal (Note 2). Second, authors who graduated from top business schools or are affiliated with the top schools tend to publish more in the top tier journals than in the second tier journals. Possible reasons for this include: (i) the top schools admit high-quality students, (ii) the top schools have better research infrastructure, (iii) faculty and students at the top schools are more exposed to topical research that will interest editors of the top journals and (iv) faculty and students at the top schools are better networked. Finally, we find that the number of seminars, colleague comments, and number of authors are all proportionally higher for papers published in the top tier journals than for papers published in the second tier journals. Following Davis and Patterson (2001), we test non-linearity in these relations to further understand the relationship.

The results show that publication in the top tier journals increases (relative to the second tier journals) as the number of seminars or of colleagues commenting on a paper increases. Thus, the likelihood of publishing in a top tier journal relative to a second tier journal increases with the number of seminars or of colleagues commenting on a paper. It is likely that papers presented at several seminars are of high quality and are authored 
by well-known researchers, as schools generally invite high-calibre scholars to present at seminars. This provides an explanation for the increase in publication rate in the top tier journals as the number of seminars that a paper is presented at increases. Turning to colleagues' comments, it is possible that researchers solicit comments from colleagues who have expertise in the research area and incrementally obtain valuable comments. Alternatively, well-known high-calibre researchers are more likely to solicit and obtain colleagues' comments on their papers.

Regarding the number of authors, we find that publication rate in the top journals increases relative to the second tier journals as the number of authors increases to four, while there is no difference in the publication rates between the two tiers when there are five or more authors. This is consistent with Davis and Patterson (2001) who find that co-authorship increases publication rates in economics but at a diminishing rate. The initial benefit of increasing co-authorship is attributable to blending of complementary skills (Holder, Langreher, \& Schroeder 2000) and division of labour (McDowell \& Melvin, 1983). Finally, we find no evidence that publication in the top tier journals increases with the number of conferences that a paper is presented at.

The literature on the factors that contribute to a successful publication in the top tier finance journals is limited. Schweser (1977) finds that $46.2 \%$ of all Journal of Finance (JF) authors educated in the U.S. received their doctorates from the top ten universities and the top twenty schools produced $72.3 \%$ of all U.S. doctorates who published in the JF. Johnson et al. (2002) examine the relation between presentations at the AFA, WFA, FMA, European Finance Association (EFA), and Utah Winter Finance Conference (UWFC) and publication rates. They find that a presentation at the UWFC increases the ex-post rate of publication in a top tier finance journal (Note $3)$.

We add to the above literature in two important ways. First, we examine the effects of a host of characteristics of articles published in the top tier finance journals. In so doing, we are the first to study the effects of the number of seminars, colleague comments, and authors on publication rate in the top tier finance journals (Note 4). Furthermore, we are able to draw broader inferences than previous studies and our work will help researchers to better direct their efforts toward areas that will increase the likelihood of publishing in a top tier finance journal. In particular, we find that the number of seminars, the number colleague comments, and author affiliation have the strongest statistical relation with publishing in the top tier journals. Second, we examine non-linear relations in our study and this sheds new light on the relation between article characteristics (the number of seminars, conferences, authors and colleague comments) and publication rate in the top tier finance journals.

The remainder of the paper is as follows: section 2 reviews the literature and develops testable hypotheses, section 3 describes the data and methodology, section 4 presents the results and section 5 concludes the paper.

\section{Literature Review and Hypotheses Development}

\subsection{Conference and Seminar Presentations}

Academics often submit new manuscripts to conferences with the aim of getting valuable feedback and improving the manuscripts. Also, newly minted PhDs or PhD students are often encouraged to present their work at conferences in order to receive feedback and improve the quality of their papers. The overriding objective for these conference presentations is to increase the chance that the papers will be published in highly regarded journals. Garvey (1979) and Montesi and Owen (2008) argue that conferences are good venues for disseminating initial findings of a research project and for receiving feedback and opinions from colleagues to strengthen the paper. In particular, authors engage in direct communication with peers and receive comments from discussants and other participants. Thus, conferences should be seen as a phase in the research process in which authors seek information from peers to strengthen and complete a paper. In fact, Montesi and Owen (2008) find the name of the conference where papers were initially presented may raise different expectations about their contributions, and conference history influences the way a paper is extended and revised. Overall, they conclude that comments and discussions help strengthen the contribution of a paper and hence, ex-post, increase the likelihood of a paper being published in a top tier journal.

Johnson et al. (2002) argue that the fact that a paper is selected for presentation at a conference provides some information that the paper passes an initial review process. They also find cross sectional variation in the information content of presenting a paper at the conferences they studied (AFA, WFA, FMA, EFA, and UWFC). In particular, presenting a paper at the UWFC increases the probability of publishing the paper in a top tier journal, suggesting a more selective conference increases the ex-post rate of publication in a top tier finance journal. This indicates that the status of a conference affects the chances of publishing a paper presented at the conference in a top journal. This leads to the formation of the following hypothesis: 
Hla: Papers presented at top tier conferences such as WFA, AFA and FMA are more likely to be published in the top tier finance journals than the second tier journals.

Also, papers presented at multiple conferences are more likely to be published in a top tier finance journal due to the fact that a large and diverse number of colleagues can offer feedback for improvements. Consistent with this, Johnson et al. (2002) find that papers presented at any two of the conferences they study (AFA, WFA, EFA, FMA, and UWFC) have a 45 percent publication rate at any journal while papers presented at any three have 53 percent publication rate. In line with this, we formulate the following hypothesis:

H1b: Papers that are presented at multiple conferences are more likely to be seasoned and more likely to be published in the top tier journals than in the second tier journals.

Another important aspect of preparing papers for publication is presenting the papers at seminars, workshops and soliciting comments from colleagues. These offer authors new ideas and different points of view, helping them to think about their work in a different manner and sharpen their contributions to the field. Thus, input from seminar and workshop participants as well as colleagues can increase the likelihood of publishing a paper in a top tier journal. Accordingly, we formulate the following two hypotheses:

H1c: Papers that are presented at several seminars are more likely to be seasoned and more likely to be published in the top tier journals than in the second tier journals.

H1d: Papers that are reviewed by a larger number of colleagues are more likely to be seasoned and more likely to be published in the top tier journals than in the second tier journals.

\subsection{Top Tier Business Schools}

Authors from top tier business schools, whether graduates or faculty members, often have the necessary resources and opportunities to present their research at top tier conferences and publish in top tier journals. Johnson et al. (2002) find that most of the presenters at the AFA, WFA and UWFC are from the top 40 business schools. Borokhovich et al. (1998) report a positive relationship between finance research (number of articles in finance journals) and affiliated business schools' reputation.

Turning to publications, Ederington (1979) finds that authors at 122 academic institutions in the U.S and Canada published in the JF and the JFQA from 1967 to 1972, and of these, the top 15 institutions accounted for half of the total pages published and only 8 institutions accounted for half of the citations. They argue that a school's prestige reflects the quality as well as quantity of articles produced. Similarly, Borokhovich et al. (1995) find that prestigious business schools are associated with high publication productivity and influence.

Kim, Morse, and Zingales (2009) find that being affiliated with one of the top 25 universities had a positive effect on location-specific component of research productivity for economics and finance faculty in the 1970s. This effect weakened is in the 1980s and disappeared in the 1990s. Karolyi (2011), on the other hand, show that the percentage of empirical paper published in the top three finance journals with at least one co-author from a "top 30 finance department" has remained steady. This leads us to formulate the following hypothesis:

H2a: Authors affiliated with tier top business schools are more likely to publish in top tier journals than in the second tier journals.

Do top-rated graduate schools produce scholars who are more likely to publish in top tier journals? Arguably, the best graduate schools equip students with superior research skills and foster an awareness of the frontier topics that are more likely to be of interest to journal editors and referees. Also, top graduate schools are more likely to attract the best students. In fact, Schweser (1977) finds that $46.2 \%$ of all JF authors educated in the U.S. received their doctorates from the top ten universities and the top twenty schools produced $72.3 \%$ of all U.S. doctorates who published in the JF. Furthermore, Laband (1986) provides evidence that publication rates are higher for graduates from top economics departments and this relation holds over time (Davis \& Patterson, 2001). Accordingly, we formulate the following:

H2b: Authors with PhDs from top tier business schools are more likely to publish in the top tier finance journals than in the second tier journals.

\subsection{Working with Co-Authors}

Co-authorship allows for productivity gains arising from joint research and writing, increasing the quality of the work and the likelihood of publishing in top tier journals. Karolyi (2011) show that there is a large increase in the number of co-authored empirical articles published in the JF, JFE and RFS in 1989, 1999 and 2009. For example in $1989,35 \%$ of papers published in these journals were written by a single author. Single authorship has declined to less than $15 \%$ in 2009. 
In addition, McDowell and Melvin (1983) argue that co-authorship increases publication rates of individuals due to division of labour. Consistent with this, Holder et al. (2000) report that an increase in quality and blending of complementary skills are the most important reasons for co-authorship (Note 5). Davis and Patterson (2001) find that co-authorship increases publication rates in the field of economics, but there are diminishing returns to co-authorship. Piette and Ross (1992) hypothesize that increasing complexity and specialization of economics research forces scholars to collaborate in order to maintain a desired level of quality. Similarly, Hollis (2001) shows that for a given individual economist, more co-authorship is associated with higher quality, greater length and greater frequency of publications (Note 6). They argue that the "effect" of adding a co-author increases the average quality by about $15 \%$.

While co-authorship leads to stronger productivity, Piette and Ross (1992) report that repeatedly cited articles or those placed early in a journal (lead articles) contain few or no co-authors. Similarly, Ederington (1979) did not find any evidence that jointly authored articles differ in importance from articles with a single author. Collectively, the evidence suggests that co-authorship improves the quality of research work and increases the likelihood of publication in top economics journals and, accordingly, we formulate the following hypothesis for the finance journals:

H3: Papers with multiple authors are more likely to be published in the top tier finance journals than in the second tier journals.

\section{Data and Methodology}

\subsection{Data}

We hand collected data on authors from ten finance journals: the Journal of Finance (JF), Journal of Financial Economics (JFE), Review of Financial Studies (RFS), Journal of Financial and Quantitative Analysis (JFQA), Journal of Banking and Finance, Journal of Financial Intermediation, Journal of Corporate Finance, Financial Management, Journal of Empirical Finance and Journal of Financial Markets. We classify the first four as the top tier journals and the remaining six as the second tier finance journals. We collected information from these journals in 2003, 2005, 2007, 2009 and 2011. This resulted in 3,156 different articles over the sample years with 7,103 different authors. Of these, 3,391 authors published 1,481 (46.93\%) articles in the top tier journals compared to 3,712 authors who published 1,675 (53.07\%) articles in the second tier finance journals. From the acknowledgement section, we gather data on number of conferences, seminars, grants, referees thanked, colleagues thanked, and whether the paper was presented at the AFA, the WFA or the FMA. Finally, we collected data on $\mathrm{PhD}$ granting institutions for each author by searching the web, author's curriculum vita, university profile or Linkedin profile. We are not able to find the $\mathrm{PhD}$ granting institution for 119 (1.67\%) authors of 95 $(3.01 \%)$ articles. Sixteen of the authors published in the top tier finance journals. In addition, there are $38(0.53 \%)$ authors with a Master's degree. Of these, 10 authors published in the top tier journals all with co-authors.

We classify a business school as a top school if it belongs to the Financial Times top 100 global business schools in 2011, and an author is affiliated with a top business school if he/she is affiliated with any of our top schools at the time of publication. We find that $35 \%$ of the authors of articles in the top ten finance journals are affiliated with a top business school. Of these authors, $72 \%$ published in the top tier finance journals. Also, $56 \%(3,954)$ of authors received their $\mathrm{PhD}$ degrees from a top business school and, of these, 2,415 (61\%) published in the top tier finance journals.

\subsection{Methodology}

To test our hypotheses, we estimated the following Logit model.

$$
\begin{gathered}
\text { Top4Journal }_{i, t}=\alpha+\beta_{1} \text { Conference }_{i, t}+\beta_{2} \text { AFA }_{i, t}+\beta_{3} \text { WFA }_{i, t}+\beta_{4} \text { FMA }_{i, t}+\beta_{5} \text { Seminar }_{i, t} \\
+\beta_{6} \text { Colleague }_{i, t}+\beta_{7} \text { Affiliation }_{i, t}+\beta_{8} \text { PhDinstitution }_{i, t} \\
+\beta_{9} \text { Author }_{i, t}+\beta_{10} \text { Grant }_{i, t}+\beta_{11} \text { Refere }_{i, t}+\varepsilon_{i, t}
\end{gathered}
$$

where Top4Journal $i_{i, t}$ is set to 1 if a paper is published in JF, JFE, RFS or JFQA in year $t$ and to 0 otherwise; Conference is the total number of conference presentations listed in the acknowledgement section; AFA (WFA) $[F M A]$ is set to 1 if the paper was presented at the AFA (AFA) [FMA] and to 0 otherwise; Seminar is the total number of seminar presentations excluding conference presentations; Colleague is set to the number of colleagues thanked excluding the editor and the referee(s); Author is the total number of authors; Affiliation is equal to the percentage of authors affiliated with the top 100 global business schools; PhDinstitution is the percentage of authors with PhDs from the top 100 global business schools; Grant is set to 1 if the paper was funded by a funding agency such as NBER, SSHRC, university internal fund, etc., and to 0 otherwise; and 
Referee is the total number of referees thanked in the acknowledgement section.

In addition to our hypothesized variables, we include control variables Grant and Referee. It is important to control for grants due to the fact that researchers with grants have additional resources. Grants increases the ability to hire graduate research assistants, to purchase databases, attend conferences and seminars and hence, can have a positive impact on the likelihood of a paper being published in a top finance journal. In addition, the number of referees reviewing an article can influence the acceptance of the article. In particular, papers reviewed by multiple referees likely face tougher scrutiny that those reviewed by a sole referee. To control for this, we count the number of referees thanked in the acknowledgement section of the article.

\section{Results}

\subsection{Descriptive Statistics}

Panel A, Table 1, reports the summary statistics of the attributes of articles published in the top tier journals and the second tier journals as well as tests of the difference in means. From the results, articles published in the top tier journals are presented at 2.52 conferences, on average, compared to 1.38 conferences for articles in the second tier finance journals. In addition, 17\% (19\%) of the articles published in the top tier journals are presented at the AFA (WFA) compared to 3\% (3\%) of the articles published in the second tier journals. In contrast, $10 \%$ of the articles published in the top tier journals were presented at the FMA compared to $14 \%$ of the articles published in the second tier journals. Articles published in the top tier journals are, on average, presented at 5.35 seminars compared to 1.61 seminars for the second tier journals.

With regards to the number of referees, we find $25 \%$ of the articles (i.e., 773 articles; 231 in the top tier journals and 542 in the second tier journals) have no information of the referees involved in the review process. For these articles, we assume one referee per article. The mean number of referees for the top tier journals is 1.16 relative to 1.25 for the second tier journals (Note 7). The mean (median) number of colleagues thanked, excluding conference and seminar participants, are 10.52 (9.00) for the top tier journals compared to 4.80 (3.00) for the second tier journals. Fifty-three percent of the authors who published in the top tier journals are affiliated with a top business school compared to only $19 \%$ of authors who published in the second tier journals. Also, $72 \%$ of the authors who published in the top tier finance journals received their $\mathrm{PhD}$ from a top business school compared to $43 \%$ of the authors who published in the second tier journals. Finally, the mean number of authors is greater for the top tier journals (2.29) than the second tier journals (2.22).

Test of all mean differences is statistically significant at the $1 \%$ level. Thus, we find that papers published in the top tier journals are more exposed to conferences and seminars, and they tend to be presented at the AFA and WFA. They also have more colleague comments and less referees, and tend to be authored by scholars who graduated from or are affiliated with a top business school.

Panel B, Table 1 provides information on sub-categories for the number of conferences, seminars, colleagues, and authors. The results show that $65 \%$ of the papers published in the second tier journals were presented at one or no conference compared to $39 \%$ for the top tier journals. In contrast, papers presented at 3, 4, 5 or $6+$ conferences tend to be published in the top tier journals relative to the second tier journals. Only $19 \%$ of papers published in the top tier journals were not presented at a seminar compared to $52 \%$ for papers published in the second tier journals. The percentage of papers published in the top tier journals that were presented at 1-4, 5-8, $9-12$, and $13+$ seminars are $32 \%, 26 \%, 14 \%$ and $9 \%$, respectively. The corresponding values for papers published in the second tier journals are $36 \%, 9 \%, 2 \%$ and $1 \%$. Looking at colleague comment, we see that only $5 \%$ of articles published in the top tier journals have no colleague comment compared to $31 \%$ for articles in the second tier journals. For the top journals, $22 \%, 15 \%$, and $17 \%$ of the articles have 9-12, 13-16, and 16+ colleague comments, respectively. The corresponding values for articles published in the second tier journals are $11 \%, 5 \%$, and $4 \%$. Lastly, our results show that $18 \%$ of the papers published in the top tier journals have one author, and $41 \%, 34 \%$, and $7 \%$ have two, three, and four or more authors (Note 8). We observed a similar trend for the second tier journals, except that articles in the top tier journals tend to have three authors while articles in the second tier journals tend to have one author. Overall, the results suggest non-linear relation the number of conferences, seminars, colleagues, and authors and publication rate in the top tier journals. 
Table 1. Summary statistics of the attributes of articles published in the top 10 finance journals.

\begin{tabular}{|c|c|c|c|c|c|c|c|}
\hline \multicolumn{8}{|l|}{ Panel A: Attributes } \\
\hline \multirow[b]{2}{*}{ Attributes } & \multirow[b]{2}{*}{ Mean } & \multicolumn{2}{|c|}{ Top 4 Finance Journals } & \multicolumn{3}{|c|}{ Top 5 to 10 Finance Journals } & \multirow[b]{2}{*}{ Difference in Mean Test } \\
\hline & & Median & Std. Dev & Mean & Median & Std. Dev & \\
\hline Conference & 2.52 & 2.00 & 2.41 & 1.38 & 1.00 & 2.35 & $13.47 * * *$ \\
\hline AFA & 0.17 & 0.00 & 0.38 & 0.03 & 0.00 & 0.17 & $14.04 * * *$ \\
\hline WFA & 0.19 & 0.00 & 0.39 & 0.03 & 0.00 & 0.17 & $15.25 * * *$ \\
\hline FMA & 0.10 & 0.00 & 0.29 & 0.14 & 0.00 & 0.35 & $-3.98 * * *$ \\
\hline Seminars & 5.35 & 4.00 & 4.96 & 1.61 & 0.00 & 2.62 & $27.27 * * *$ \\
\hline Grant & 0.39 & 0.00 & 0.49 & 0.36 & 0.00 & 0.48 & $1.92 *$ \\
\hline Referee & 1.16 & 1.00 & 0.39 & 1.25 & 1.00 & 0.47 & $-5.43 * * *$ \\
\hline Colleague & 10.47 & 9.00 & 7.37 & 4.80 & 3.00 & 6.67 & $26.13 * * *$ \\
\hline Author & 2.29 & 2.00 & 0.85 & 2.22 & 2.00 & 0.86 & $2.63 * * *$ \\
\hline Affiliation & 0.53 & 0.50 & 0.42 & 0.19 & 0.00 & 0.33 & $26.09 * * *$ \\
\hline PhDinstitution & 0.72 & 1.00 & 0.36 & 0.43 & 0.33 & 0.41 & $20.94 * * *$ \\
\hline \multicolumn{8}{|c|}{ Panel B: Breakdown of conference, seminar, people and author } \\
\hline Conference 0 & 0.28 & 0.00 & 0.45 & 0.49 & 0.00 & 0.50 & $-12.00 * * *$ \\
\hline Conference 1 & 0.11 & 0.00 & 0.32 & 0.16 & 0.00 & 0.37 & $-3.76^{* * *}$ \\
\hline Conference 2 & 0.16 & 0.00 & 0.37 & 0.15 & 0.00 & 0.35 & 1.23 \\
\hline Conference 3 & 0.14 & 0.00 & 0.35 & 0.08 & 0.00 & 0.28 & $4.99 * * *$ \\
\hline Conference 4 & 0.11 & 0.00 & 0.31 & 0.06 & 0.00 & 0.24 & $5.19^{* * *}$ \\
\hline Conference 5 & 0.08 & 0.00 & 0.27 & 0.03 & 0.00 & 0.16 & $8.13 * * *$ \\
\hline Conference $6+$ & 0.11 & 0.00 & 0.32 & 0.04 & 0.00 & 0.19 & $8.14 * * *$ \\
\hline Seminar 0 & 0.19 & 0.00 & 0.39 & 0.52 & 1.00 & 0.50 & $-20.45^{* * *}$ \\
\hline Seminar 1-4 & 0.32 & 0.00 & 0.47 & 0.36 & 0.00 & 0.48 & $-2.60 * * *$ \\
\hline Seminar 5-8 & 0.26 & 0.00 & 0.44 & 0.09 & 0.00 & 0.28 & $13.24 * * *$ \\
\hline Seminar 9-12 & 0.14 & 0.00 & 0.35 & 0.02 & 0.00 & 0.14 & $13.03 * * *$ \\
\hline Seminar 13+ & 0.09 & 0.00 & 0.29 & 0.01 & 0.00 & 0.10 & $10.97 * * *$ \\
\hline Colleague 0 & 0.05 & 0.00 & 0.23 & 0.31 & 0.00 & 0.46 & $-19.37 * * *$ \\
\hline Colleague 1-4 & 0.15 & 0.00 & 0.36 & 0.28 & 0.00 & 0.45 & $-8.77 * *$ \\
\hline Colleague 5-8 & 0.26 & 0.00 & 0.44 & 0.22 & 0.00 & 0.41 & $2.72 * * *$ \\
\hline Colleague 9-12 & 0.22 & 0.00 & 0.41 & 0.11 & 0.00 & 0.31 & $8.46^{* * *}$ \\
\hline Colleague 13-16 & 0.15 & 0.00 & 0.36 & 0.05 & 0.00 & 0.23 & $9.20 * * *$ \\
\hline Colleague $16+$ & 0.17 & 0.00 & 0.38 & 0.04 & 0.00 & 0.18 & $13.12 * * *$ \\
\hline Author 1 & 0.18 & 0.00 & 0.39 & 0.21 & 0.00 & 0.41 & $-1.96^{* *}$ \\
\hline Author 2 & 0.41 & 0.00 & 0.49 & 0.43 & 0.00 & 0.50 & 0.98 \\
\hline Author 3 & 0.34 & 0.00 & 0.47 & 0.30 & 0.00 & 0.46 & $2.64 * * *$ \\
\hline Author 4 & 0.06 & 0.00 & 0.23 & 0.05 & 0.00 & 0.23 & 0.13 \\
\hline Author 5+ & 0.01 & 0.00 & 0.08 & 0.01 & 0.00 & 0.08 & 0.04 \\
\hline
\end{tabular}

Differences in mean test are based on t-tests. The number of observations is 1,481 and 1,675 for the top 4 and top 5 to10 groups, respectively. *** indicate significance at the $1 \%$ level of test.

** indicate significance at the $5 \%$ level of test.

* indicates significance at the $10 \%$ level of test.

We provide additional descriptions for some of the influential variables for publication in the top tier finance journals versus publications in the second tier finance journals (number of conferences, number of seminars, author affiliation and $\mathrm{PhD}$ granting institutions). Figure 1 shows the average number of conference presentations for the journals we investigate by year. From the figure, we see an upward trend in the number of conference presentations across the journals, especially for the top tier journals. Figure 2 shows the mean number of seminar presentations by journal and year. For the Journal of Finance, we see a large increase in the mean number of seminar presentations in more recent years (2009 and 2011), and papers published in the journal have the highest seminar presentations in these years than any other journal we study. Also, we see an upward trend in the number of seminar presentations for papers published in the JFQA. 


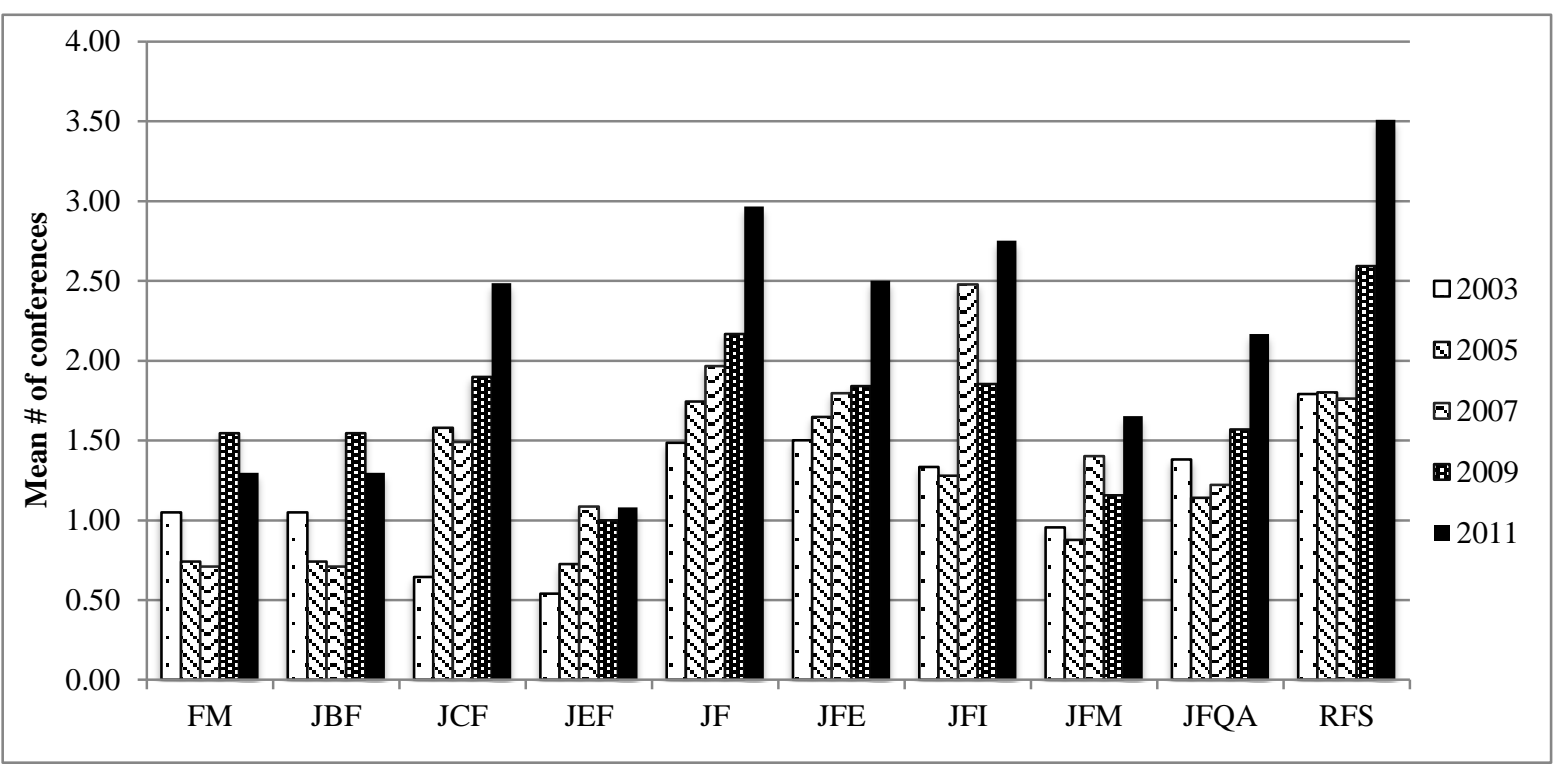

Figure 1. Mean number of conference presentations by year and journal

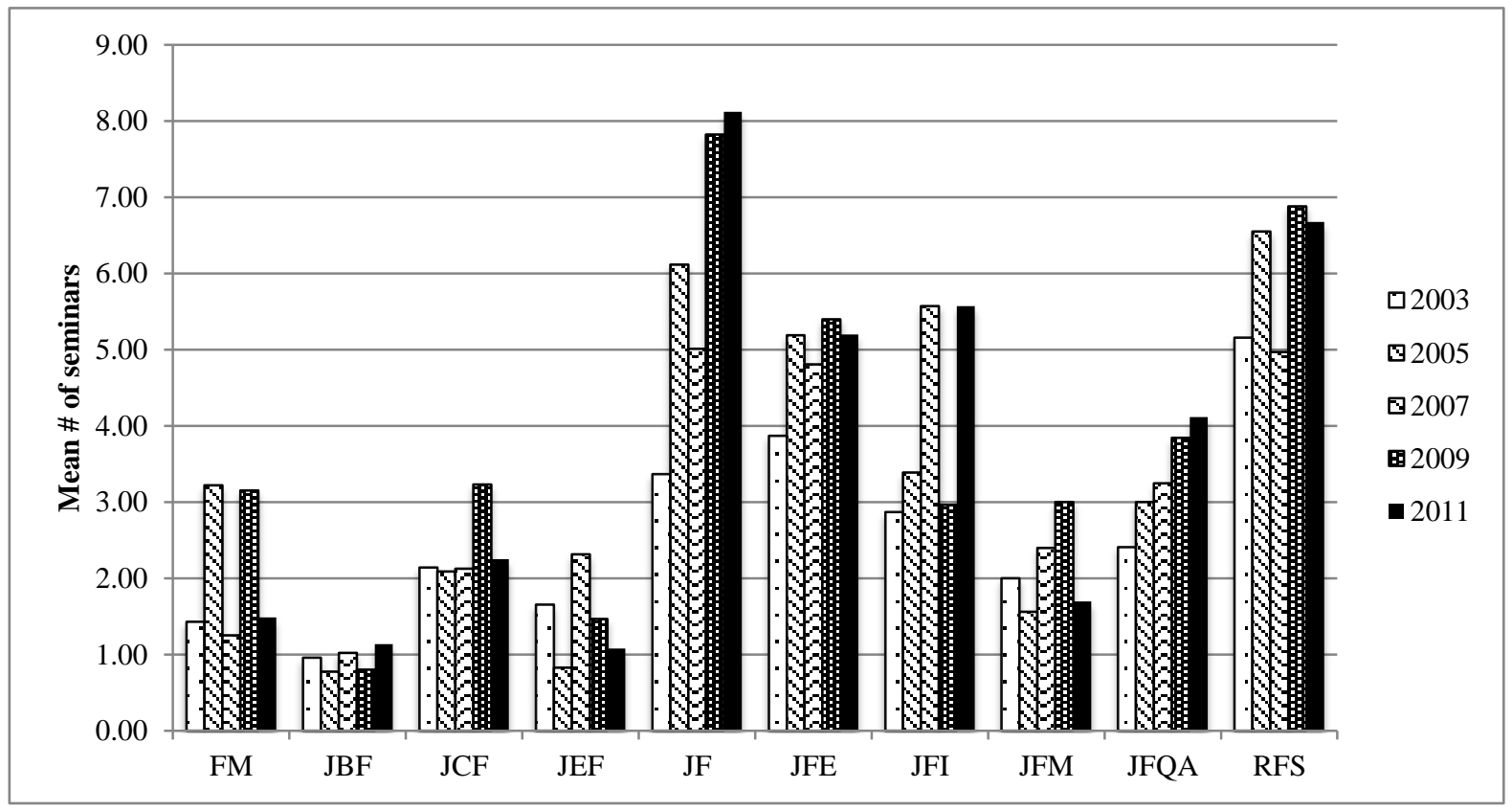

Figure 2. Mean number of seminar presentations by year and journal

Table 2 reports the percentage of authors affiliated with the top global business schools and authors receiving their PhD from the top schools by year and journal. In Panel A, the percentage of authors who publish in the top tier journals and are affiliated with the top business schools appears more stable across the sample period than that for the second tier journals. Panel B results are similar, and the percentage of authors with PhDs from top business schools appears more stable than that for the second tier journals. 
Table 2. Mean and median statistics by year and journal for authors PhD degree from and affiliated to the top 100 business schools

\begin{tabular}{|c|c|c|c|c|c|c|c|c|c|c|c|c|}
\hline \multicolumn{13}{|c|}{ Panel A: Percentage Author affiliated with top 100 business schools } \\
\hline & FM & JBF & JCF & JEF & $\mathrm{JF}$ & JFE & JFI & JFM & JFQA & RFS & Mean & Med \\
\hline 2003 & 0.20 & 0.12 & 0.17 & 0.40 & 0.55 & 0.56 & 0.23 & 0.28 & 0.27 & 0.55 & 0.35 & 0.00 \\
\hline 2005 & 0.33 & 0.14 & 0.30 & 0.23 & 0.56 & 0.61 & 0.28 & 0.52 & 0.31 & 0.66 & 0.38 & 0.33 \\
\hline 2007 & 0.35 & 0.11 & 0.24 & 0.25 & 0.56 & 0.54 & 0.25 & 0.19 & 0.30 & 0.66 & 0.34 & 0.00 \\
\hline 2009 & 0.20 & 0.14 & 0.34 & 0.26 & 0.59 & 0.56 & 0.24 & 0.24 & 0.28 & 0.61 & 0.36 & 0.00 \\
\hline 2011 & 0.24 & 0.12 & 0.21 & 0.14 & 0.63 & 0.48 & 0.33 & 0.28 & 0.29 & 0.58 & 0.31 & 0.00 \\
\hline 2003-11 Mean & 0.26 & 0.12 & 0.25 & 0.25 & 0.57 & 0.54 & 0.27 & 0.29 & 0.29 & 0.61 & & \\
\hline 2003-11 Median & 0.00 & 0.00 & 0.00 & 0.00 & 0.67 & 0.50 & 0.00 & 0.00 & 0.00 & 0.67 & & \\
\hline \multicolumn{13}{|c|}{ Panel B: Percentage of Authors receiving their PhD from a top 100 Business School } \\
\hline & FM & JBF & JCF & JEF & $\mathrm{JF}$ & JFE & JFI & JFM & JFQA & RFS & Mean & Med \\
\hline 2003 & 0.48 & 0.47 & 0.45 & 0.66 & 0.70 & 0.68 & 0.70 & 0.66 & 0.61 & 0.76 & 0.61 & 0.67 \\
\hline 2005 & 0.57 & 0.44 & 0.52 & 0.39 & 0.75 & 0.72 & 0.40 & 0.65 & 0.59 & 0.78 & 0.59 & 0.67 \\
\hline 2007 & 0.51 & 0.37 & 0.47 & 0.62 & 0.82 & 0.74 & 0.60 & 0.55 & 0.48 & 0.81 & 0.58 & 0.67 \\
\hline 2009 & 0.42 & 0.33 & 0.48 & 0.43 & 0.81 & 0.73 & 0.74 & 0.57 & 0.59 & 0.77 & 0.57 & 0.50 \\
\hline 2011 & 0.47 & 0.31 & 0.38 & 0.41 & 0.75 & 0.66 & 0.55 & 0.55 & 0.57 & 0.78 & 0.51 & 0.50 \\
\hline 2003-11 Mean & 0.48 & 0.37 & 0.45 & 0.49 & 0.77 & 0.70 & 0.60 & 0.59 & 0.57 & 0.78 & & \\
\hline 2003-11 Median & 0.50 & 0.33 & 0.50 & 0.50 & 1.00 & 1.00 & 0.67 & 0.55 & 0.50 & 1.00 & & \\
\hline
\end{tabular}

\subsection{Regression Results}

In this section, we estimate the Logistic regression of Equation (1) to analyze the relation between the characteristics of articles and publication rate in the top versus the second tier journals in a multivariate framework. From the results, presented in Table 3, the coefficient estimate for the indicator variable $A F A$ is 1.01 $(\mathrm{z}$-value $=5.31)$ and that for WFA is $1.12(\mathrm{z}$-value $=5.82)$. In contrast, the coefficient estimate for FMA is -0.71 (z-value -4.48). These suggest that papers published in the top tier journals tend to be presented at the AFA and the WFA than papers published in the second tier finance journals, whilst papers published in the second tier journals tend to be presented at the FMA than papers published in the top tier journals. This likely reflects the fact that the WFA and AFA are more selective conferences, accepting only high quality and cutting edge research papers that are more likely to be accepted by the top tier journals. This is in line with Johnson et al. (2002) who report that smaller and more selective conferences increase the ex-post rate of publication in a top tier finance journal.

The coefficient estimate for Conference is -0.01 with $z$-value of -0.24 , suggesting there is no significant difference in the number of conference presentations for articles published in the top tier journals and in the second tier journals. This rejects hypothesis $H 1 b$. Our finding, however, does not conflict with that of Johnson et al. (2002) who find that articles presented at any three of the five conferences they studied lead to a 53\% publication rate in any journal, while articles presented at any two of the conferences have a lower publication rate $(45 \%)$. Our focus is different, we examine the characteristics of articles published in the top tier finance journals versus the second tier journals, and find that the number of conference presentations is not statistically different for articles published in these two group journals.

The coefficient estimate for Seminar is 0.14 (z-value $=9.14$ ), implying papers published in the top tier journals tend to be presented at more seminars than papers published in the second tier journals. This result supports Hlc. This lends credence to the argument that papers presented at seminars tend to benefit from longer discussions and face more scrutiny than papers presented at conferences. Alternatively, business schools often only invite high-calibre scholars to present at seminars and, hence, only high-calibre scholars are likely to present papers at several seminars, leading to a positive coefficient on Seminar.

The coefficient estimate for Colleague is 0.10 with z-value of 10.47 , suggesting papers published in the top tier finance journals tend to be reviewed by more colleagues than papers published in the second tier journals. This supports $H l d$, and it indicates that comments and scrutiny from colleagues play an important role in improving the quality of the paper and, hence, increase the probability that the paper will be accepted in a top tier finance journal.

The estimate of the coefficient on Authors is 0.15 (z-value $=2.75$ ), suggesting articles published in the top tier finance journals have a higher number of authors than articles published in the second tier journals. The results 
suggest that co-authorship improves the quality of a paper through the blending of complementary skills of different authors (e.g., Holder et al., 2000) leading to higher quality papers than papers that are solo authored.

Table 3. Logistic regression of publications in the top 4 finance journals

\begin{tabular}{lcc}
\hline & Coefficient & z-statistics \\
\hline Conference & -0.01 & -0.24 \\
AFA & 1.01 & $5.31^{* * * *}$ \\
WFA & 1.12 & $5.82^{* * * *}$ \\
FMA & -0.71 & $-4.48^{* * *}$ \\
Seminars & 0.14 & $9.14^{* * *}$ \\
Grant & -0.08 & -0.82 \\
Referee & -0.77 & $-6.97^{* * *}$ \\
Colleague & 0.10 & $10.47^{* * *}$ \\
Author & 0.15 & $2.75^{* * *}$ \\
Affiliation & 1.21 & $9.39^{* * *}$ \\
PhDinstitution & 0.74 & $5.85^{* * *}$ \\
Intercept & -1.55 & $-7.55^{* * *}$ \\
\hline Obs. & 3,156 & \\
Pseudo R2 & 0.306 & \\
LR chi2(11) & $1,336.5$ & \\
Prob > chi2 & 0.00 & \\
Log likelihood & $-1,513.32$ & \\
\hline
\end{tabular}

The table reports the estimates of Equation (1). The dependent variable is set to one if an article is published in the top four journals and to zero if published in the next six journals.

*** indicate significance at the $1 \%$ level of test.

** indicate significance at the $5 \%$ level of test.

* indicates significance at the $10 \%$ level of test.

The coefficient estimate on Affiliation is 1.21 with z-value of 9.39, suggesting authors from the top 100 business schools tend to publish in the top tier finance journals than the second tier journals. This supports $H 2 a$, suggesting that author affiliation with a top business school increases the likelihood of publishing in the top tier finance journals versus publishing in the second tier journal. The results are consistent with the findings of Borokhovich et al. (1998), who find that author affiliation is an important determinant of publishing in the top tier journals.

The estimate of the coefficient on PhDinstitution is 0.74 with z-value of 5.85. Thus, papers published in the top tier journals tend to be published by authors with PhDs from the top 100 business schools than papers published in the second tier journals. This likely reflects the fact that the top schools attract the best students and these students also benefit from being exposed to the frontier topics that are likely to be of interest to top journal editors and referees. The results are consistent with the findings of Schweser (1977) who studied JF articles from 1964 to 1975.

The coefficient estimate for Grant is -0.08 (z-value $=-0.82$ ), suggesting there is no difference in the proportions of articles that received grants and are published in the top versus the second tier journals. The estimate of the coefficient on Referee is -0.77 ( $\mathrm{z}$-value $=-6.97$ ), suggesting that articles published in the second tier journals are review by more referees than articles published in the first tier journals. This supports anecdotal evidence that the top tier journals tend to use a one referee system for their reviews more than the second tier journals.

\subsection{Non-Linearity}

We examine whether presenting at additional conferences and seminars, soliciting additional colleague's comment, and additional authors exhibit diminishing returns with respect to publishing in the top tier journals versus the second tier journals. Specifically, we construct a binary variable Conference $(i)$, for $i=1,2, \ldots, 6+$, which is set to 1 if a paper was presented at $i$ conferences and zero otherwise. Similarly, we construct variables for the number of authors $(A u t h o r(i))$. For the numbers of seminar presentations and of colleague commenting on a papers, we construct the binary variable as follows: Seminar $(i-j)$ is set to one if the paper is presented at $i$ to $j$ seminars and similarly, we construct Colleague $(i-j)$ for the number of colleagues' comments. The results from this expanded version of Equation (1) are reported in Table 4. 
Table 4. Logistic regression of publications in the top four finance journals

\begin{tabular}{|c|c|c|}
\hline & Coefficient & z-statistics \\
\hline Conference(1) & -0.38 & $-2.59 * *$ \\
\hline Conference(2) & -0.16 & -1.05 \\
\hline Conference(3) & 0.09 & 0.48 \\
\hline Conference(4) & -0.30 & -1.48 \\
\hline Conference(5) & 0.07 & 0.26 \\
\hline Conference $(6+)$ & -0.08 & -0.31 \\
\hline $\mathrm{AFA}$ & 1.00 & $5.19 * * *$ \\
\hline WFA & 1.11 & $5.74 * * *$ \\
\hline FMA & -0.79 & $-5.00 * * *$ \\
\hline Seminar(1-4) & 0.25 & $2.14 * *$ \\
\hline Seminar(5-8) & 0.99 & $6.62 * * *$ \\
\hline Seminar(9-12) & 1.55 & $6.64 * * *$ \\
\hline Seminar(13+) & 1.62 & $5.23 * * *$ \\
\hline Grant & -0.08 & -0.85 \\
\hline Referee & -0.79 & $-7.13 * * *$ \\
\hline Colleague(1-4) & 0.97 & $5.99 * * *$ \\
\hline Colleague(5-8) & 1.60 & $9.82 * * *$ \\
\hline Colleague(9-12) & 1.80 & $10.02 * * *$ \\
\hline Colleague(13-16) & 1.96 & $9.46^{* * *}$ \\
\hline Colleague(17+) & 2.24 & $9.73 * * *$ \\
\hline Author(2) & 0.22 & $1.71 *$ \\
\hline Author(3) & 0.42 & $3.09^{* * *}$ \\
\hline Author(4) & 0.50 & $2.29 * *$ \\
\hline Author(5+) & 0.04 & 0.06 \\
\hline Affiliation & 1.24 & $9.49 * * *$ \\
\hline PhDinstitution & 0.73 & $5.66^{* * *}$ \\
\hline Intercept & -1.99 & $-9.27 * * *$ \\
\hline Obs. & 3,156 & \\
\hline Pseudo R2 & 0.32 & \\
\hline LR chi2(26) & $1,393.31$ & \\
\hline Prob > chi 2 & 0.00 & \\
\hline Log likelihood & $-1,484.95$ & \\
\hline
\end{tabular}

The table reports an extended version of Equation (1) to analyze non-linear relations. The dependent variable is set to one if an article is published in the top four journals and to zero if published in the next six journals. Conference $(i)$ is a binary variable equal to 1 if an article is presented at $i$ conferences and zero otherwise. Variable Author $(i)$ is similarly defined. Seminar $(i-j)$ is a binary variable equal to 1 if a paper is presented at $i$ to $j$ seminars and zero otherwise. Variable Colleague $(i-j)$ is similarly defined.

*** indicate significance at the $1 \%$ level of test.

** indicate significance at the $5 \%$ level of test.

* indicates significance at the $10 \%$ level of test.

From the results, we do not see a systematic pattern in the coefficient estimates on Conference( $i$ ). In particular, none of the coefficient estimate is statistically significant at conventional levels of test with the exception of the estimate for Conference( 1$)$, which is negative and significant $(-0.38$; $\mathrm{z}$-value $=-2.59)$. This suggests that papers published in the second tier journals tend to be presented at one conference more than papers published in the top tier journals, while there is no difference in the papers presented at two or more conferences.

With regards to seminar presentations, we see a distinct increase in the coefficient estimates as the number of seminars increases. In particular, the coefficient estimates are $0.25(\mathrm{z}$-value $=2.14), 0.99(\mathrm{z}$-value $=6.62), 1.55$ $(z$-value $=6.64)$, and $1.62(z$-value $=5.23)$ for Seminar (1-4), Seminar(5-8), Seminar(9-12), and Seminar(13+), respectively. This sheds light on our finding that papers published in the top tier journals tend to be presented at more seminars than papers published in the second tier journals. In particular, we see that this difference is stronger the higher the number of seminars that the papers are presented at. This indicates that the likelihood of publishing in the top tier finance journals vis a vis the second tier journals increases with the number of seminar presentations. It is possible that papers presented at several seminars are of high quality and are authored by 
well-known researchers, since many schools only invite high calibre scholars to do seminar presentations. In addition, seminar presentations are likely to face more scrutiny from colleagues than conference presentations, resulting in obtaining incremental feedbacks from seminar participants.

We also observe non-linearity in the relation between publication in the top tier journals and the number of colleagues thanked in the acknowledgement section of the papers. From the table, the coefficient estimates are $0.97(\mathrm{z}$-value $=5.99), 1.60(\mathrm{z}$-value $=9.82), 1.80(\mathrm{z}$-value = 10.02), $1.96(\mathrm{z}$-value $=9.46)$, and $2.24(\mathrm{z}$-value $=$ 9.73) for Colleague(1-4), Colleague(5-8), Colleague(9-12), Colleague(13-16), and Colleague(17+), respectively. Thus, it is possible that colleagues give valuable comments on a paper and this increases the likelihood of publishing them in the top tier finance journals than in the second tier journals. Also, well-known high-calibre researchers are more able to solicit and obtain colleagues' comments on their papers. Thus, papers with several colleagues' comments are likely to be of high quality leading to a stronger relation between publication in the top tier journals and colleagues' comments as the number of comments increases.

Turning to the number of authors, we see that the coefficient estimates on Author(2), Author(3), Author(4), and Author $(5+)$ are $0.22(\mathrm{z}$-value $=1.71), 0.42(\mathrm{z}$-value $=3.09), 0.50(\mathrm{z}$-value $=2.29)$, and $0.04(\mathrm{z}$-value $=0.04)$. These suggest that publication rate in the top journals increases relative to the second tier journals as the number of authors increases to four, while five or more authors make no difference in the publication rates. This is consistent with other studies that find that increasing authorship increases publication rate but at a diminishing return (e.g., Davis and Patterson 2001). McDowell and Melvin (1983) attribute the increase in publication rate to division of labour and Holder, Langreher and Schroeder (2000) attribute it to blending of complementary skills. The lack of a difference in publication rates for five or more authors likely reflect the difficulties with co-ordinating work among a large group of authors and the associated free-rider problems.

\subsection{Robustness Check}

It is possible that papers with more than one author are more likely to be presented at more conferences and more seminars by the different authors than solo authored articles. Also, the different authors can solicit more colleague comments than a solo author. Accordingly, we scale the number of conferences (Conference), the number of seminars (Seminars) and the number of colleagues who commented on a paper (Colleague) by total authorship to create three per author variables and re-estimate equation (1). The results (not reported) are very similar to those in Table 3.

\section{Conclusions}

We investigate the characteristics of papers published in the top tier finance journals (JF, JF, RFS, and JFQA) versus those of papers published in the second tier (next six) journals. Based on the literature on publications in economics and finance, we construct several hypotheses about the characteristics of articles published in the top journals versus those published in the second tier journals, and document several results. We find that papers published in the top tier journals tend to presented at the AFA and the WFA more than papers published in the second tier journals. In addition, papers published in the top tier journals tend to be presented at more seminars, have more colleague comments, and have a higher number of authors than articles published in the second tier journals. Finally, we find that authors of the papers published in the top tier journals tend to be affiliated with or have $\mathrm{PhDs}$ from the top business schools than the authors of the papers published in the second tier journals.

Next, we examine whether additional conferences, seminars, colleague comments, and authors are important in publishing papers in the top tier journals versus in the second tier journals. Our results show that the incremental conferences are not important in publishing papers in the top tier journals versus the second tier journals. In contrast, papers presented at more seminars tend to be published more in the top tier journals relative to the second tier journals than papers presented at few seminars. This suggests that the probability of publishing a paper in a top tier journal versus a second tier journals increases with the number of seminars. Similarly, we find that papers that benefit from more colleague comments tend to be published in the top tier journals more than the second tier journals than papers that receive few colleague comments. Also, publication rate in the top journals increases relative to the second tier journals as the number of authors increases to four, while there is no difference in the publication rates between the two tiers when there are five or more authors. These results suggest that the number seminars, colleague comments, and authors (up to four) increase the chances of publishing a paper in the top tier journals versus the second tier journals, while conference presentations do not (with the exception of the WFA and the AFA).

\section{Acknowledgements}

We acknowledge the research assistantship of Shirin Shams and Sagar Bhattarai in collecting the publication 
data. We also thank participations at the 2015 Eastern Finance Association meeting in New Orleans, USA.

\section{References}

Borokhovich, K. A., Bricker, R. J., Brunarski, K. R., \& Simkins, B. J. (1998). Finance research productivity and influence by topic area. Journal of Financial Education, 24, 8-20.

Borokhovich, K. A., Bricker, R. J., Brunarski, K. R., \& Simkins, B. J. (1995). Finance research productivity and influence. Journal of Finance, 50, 1691-1717. http://dx.doi.org/10.1111/j.1540-6261.1995.tb05193.x

Davis, J. C., \& Patterson, D. M. (2001). Determinants of variations in journal publication rates of economists. The American Economist, 45, 86-91. http://dx.doi.org/10.1177/056943450104500109

Ederington, L. H. (1979). Aspects of the production of significant financial research. Journal of Finance, 34, 777-786. http://dx.doi.org/10.1111/j.1540-6261.1979.tb02142.x

Garvey, W. G. (1979). Communication: The essence of science. Facilitating information exchange among librarians, scientists, engineers and students. Oxford, Pergamon.

Holder, M. E., Langreher, F. W., \& Schroeder, D. M. (2000). Finance journal coauthorship: How do coauthors in very select journals evaluate the experience? Financial Practice and Education, 142-152.

Hollis, A. (2001). Co-authorship and the output of academic economists. Labour Economics, 8, 503-530. http://dx.doi.org/10.1016/S0927-5371(01)00041-0

Johnson, S. J., Kalay, A., \& Schallheim, J. (2002). Does publication follow presentation? The information content of presentation at refereed finance conferences. Working paper.

Karolyi, G. A. (2011). The ultimate irrelevance proposition in finance? Financial Review, 46, 485-512. http://dx.doi.org/10.1111/j.1540-6288.2011.00309.x

Kim, E. H., Morse, A., \& Zingales, L. (2009). Are elite universities losing their competitive edge? Journal of Financial Economics, 93, 353-381. http://dx.doi.org/10.1016/j.jfineco.2008.09.007

Laband, D. N. (1986). A ranking of Top U.S. economics departments by research productivity of graduates. Journal of Economic Education, 17, 70-76.

McDowell, J. M., \& Melvin, M. (1983). The determinants of co-authorship: An analysis of the economic literature. Review of Economics and Statistics, 65, 155-160. http://dx.doi.org/10.2307/1924423

Montesi, M., \& Owen, J. M. (2008). From conference to journal publication: How conference papers in Software Engineering are extended for publication in journals. Journal of the American Society for Information Science and Technology, 59, 816-829. http://dx.doi.org/10.1002/asi.20805

Piette, M. J., \& Ross, K. L. (1992). An analysis of the determinants of co-authorship in economics. Journal of Economic Education, 23, 277-283. http://dx.doi.org/10.1080/00220485.1992.10844762

Schweser, C. (1977). The doctoral origins of contributors to the Journal of Finance from 1964 through 1975. Journal of Finance, 32, 908-910. http://dx.doi.org/10.1111/j.1540-6261.1977.tb01997.x

\section{Notes}

Note 1. We classify Journal of Finance (JF), Journal of Financial Economics (JFE), Review of Financial Studies (RFS), Journal of Financial and Quantitative Analysis (JFQA) as the top tier finance journals and Journal of Banking and Finance, Journal of Financial Intermediation, Journal of Corporate Finance, Financial Management, Journal of Empirical Finance and Journal of Financial.

Note 2. A negative relation between FMA and publication in the top tier journals does not mean presenting a paper at the FMA reduces the likelihood of publishing it in a top tier journal relative to a second tier journal. Rather, the AFA and the WFA accept fewer papers than the FMA and, since only a limit number of papers can be published in the top journals, more of the papers presented at the FMA end up in the second tier journals than in the top tier journals.

Note 3. Their top tier journals include the Journal of Finance, Journal of Financial Economics, Review of Financial Studies and the Journal of Financial and Quantitative Analysis.

Note 4. Other works have looked at multiple authorships in economics and other areas.

Note 5. Holder et al. (2000) surveyed coauthors (1992 to 1994) in Financial Management, Journal of Finance and Journal of Financial Economics. 
Note 6. Hollis (2001) argues that after discounting by the number of authors, co-authorship is negatively related to output.

Note 7. Our results are robust when we assume zero or two referees.

Note 8. This finding is similar to those presented by Karolyi (2011) for papers published in JF, JFE and RFS in 2009.

\section{Copyrights}

Copyright for this article is retained by the author(s), with first publication rights granted to the journal.

This is an open-access article distributed under the terms and conditions of the Creative Commons Attribution license (http://creativecommons.org/licenses/by/4.0/). 